\title{
Updating warning systems for climate hazards: Can navigation satellites help?
}

\author{
John Handmer \\ Centre for Risk \& Community Safety, RMIT, Melbourne \\ Suelynn Choy \\ Centre for Risk \& Community Safety, RMIT, Melbourne \\ Naohiko Kohtake \\ Keio University, Tokyo
}

Summary: Warning systems are relied on worldwide as part of disaster risk reduction.

The traditional model of a government monopolistic system supplying warnings through a broadcast approach is now challenged by new media, mobile technologies and the accompanying expectations of individualised warnings to personal mobile devices. We examine this situation, and one novel approach - the use of an augmented signal from the next generation of Japanese positioning satellites - to providing individual warnings to personal devices wherever their owners are. We conclude that delivery to personal devices is feasible and already happening to some extent. Linking these new official systems with the multiple information flows of social media and crowdsourcing remains a major challenge.

\section{Introduction}

Warning systems are increasing relied on to reduce the risk of disaster by empowering people to improve their safety. These systems typically require the integration of a top-down official alert, with a bottom-up understanding of that alert and their personal risk related circumstances by those receiving the warning. However, the interaction between the official and the people is problematic with the consequence that safety is often not improved: official systems have many technical and other limitations, and those at risk often fail to see the relevance of official communications. These systems are based on a linear flow of information along a complex chain of authority to those thought to be at risk. But the warning paradigm is changing rapidly. Social media and mobile technologies enable communities to generate and share their own warnings and information, which are often more up-to-date and sensitive to local circumstances than official communications. Increasingly, they can also provide information to the official system - some Australian fire 
and emergency management services monitor twitter for this purpose. Despite concerns about the legitimacy and accuracy of such information, these 'backchannel' communications are becoming increasingly prevalent during emergencies. This important aspect of the warning process is entirely dependent on the normal functioning of telecommunication infrastructure. At the same time there is anecdotal evidence from fire and emergency management agencies that public expectations, fueled by the near universality of personal mobile devices and social media, have risen to the extent that people increasingly expect a personal warning wherever they are.

A major challenge is to have the official warning system, with its environmental monitoring and predictive capacity, interact positively with the social media and personal devices used by most people. If this is achieved, the reliability of the overall warning system could be enhanced. One promising approach is based on joining the potential of mobile devices with next generation satellite-based navigation systems, such as the system being established by Japan. Such satellite systems also have the potential to provide redundancy and surge capacity for conventional terrestrial based communication arrangements.

In this paper we summarise what warning systems for natural hazards are, how they are designed and what they are intended to achieve - and some of the difficulties in achieving success. We also examine the impact of new technology and social media, and set out an example of an emerging technology and its potential to address some of the long standing issues with warning systems, and the remaining challenges.

\section{Warning systems}

Ideally, warnings provide a signal to that those at risk from disasters so they can take action to improve their safety and reduce losses. "Losses" refer to tangible assets typically valued in money terms such as buildings, livestock, and telecommunications facilities; and to consequential or indirect losses as a result of disruption to commerce, government and people's lives (BTE 2001). Losses can also be intangible such as lives, psychological trauma and ecosystem services. Warnings are produced by a mix of technology and human and organisational factors, with many decision-nodes and points of potential failure (Handmer 2000). As a result, many warning systems fail to provide signals in time or in a form that is useful to those at risk. Even when timely signals are provided, people and organisations often do not take the actions necessary to protect their safety and livelihoods.

Warnings systems need to take account of the day-to-day pressures, beliefs and expectations of the people intended to take action on receipt of a warning. This means that systems need to use media familiar to the intended audience(s) and design messages that have meaning to them (Australian Government 2008). The audiences or groups at risk are many and varied, 
such as businesses, tourists, elderly, schools, those in transit. Contemporary best practice in risk communication is that warning design should be based on local needs and expectations, and have meaning for those at risk: there needs to be a shared understanding between those issuing the warning and those receiving it (EMA 2009; UN-ISDR 2006).

For this to happen, there needs to be mutual learning between those with formal responsibility for the warnings and those at risk. The important implication here is that those at risk need to be involved with warning system design and operation. Warnings need to be delivered by a variety of modes appropriate for the audience in a timely manner so as to allow for people to confirm what they have to do and to take action in time. Warnings need to make sure people know what they can do to improve their safety and reduce losses.

Warnings issued through official channels are almost always complemented by unofficial or informal messages - unless the official warnings are seen as irrelevant (Parker \& Handmer 1998). These are messages sent and received through personal networks both to warn and to confirm official warnings and other signs, such as environmental cues, of an impending emergency. These informal networks are often key to the rapid spread of warnings and to people's ability to obtain credible confirmation of the warning. In addition, very often, informal channels are the only way people receive warnings, because they deliver messages directly to people via media and in language that they understand.

\section{Warning system design}

In Australia the essence of what can be viewed as the traditional approach to warning system design is captured in the Guide for Flood Warnings (EMA 2009). Although the guide is at pains to point out that warnings must be based on local knowledge and that knowledge of local circumstances is key to success, warning systems are shown as a more or less linear chain or process that includes multiple organisations only some of which are under the control of government (Handmer 2009):

- $\quad$ 'Prediction: detecting environmental conditions that lead to the problem, and predicting its severity;

- Interpretation: identifying in advance the impacts of the predicted event on communities at risk;

- Message construction: devising the content of the message which will warn people of the impending event;

- $\quad$ Communication: disseminating accurate warning information in a timely fashion to people and organisations likely to be affected by the event; 
- $\quad$ Protective behaviour: generating appropriate and timely actions from the threatened community and from the agencies involved; and

- $\quad$ Review: examining the various aspects of the system with a view to improving its performance.'

This approach can work very well and is key in many economic sectors including transport, energy supply, offshore oil rigs, etc. However, it is a supply rather than demand approach: people are given information often in a form that means little to them, and without the ability to interact with the information, for example to establish exactly what the implications are for them and their households. This has generally been the case even though the warnings should be based on an assessment of local risks and vulnerabilities. In the time pressured situation of an impending emergency, this approach assumes that the official warning agency has a monopoly on relevant information.

Overlying the system elements are some basic design principles for warnings. These are not always explicit, but are important in how warning systems actually work to improve safety and reduce loss. The principles include compatibility with the existing telecommunications networks targeted at those at risk, underpinned by education and awareness raising activities. Note that in practice addition principles are used, for example the need to ensure that warnings do not exclude classes of people.

For the list of national design principles see:

https://www.em.gov.au/Emergency-Warnings/Pages/Emergencywarningsguidelinesandpri nciples.aspx

\section{Issues and difficulties}

After major emergencies and disasters, questions are typically raised about the inadequacy of warnings, and there have recently been some high profile failures of warning systems, and cases where the public expected warnings but there were none - e.g. Hurricane Katrina and New Orleans (Handmer 2006). Part of the difficulty is that a warning that reaches most people but fails to reach the most vulnerable groups or facilities will likely not be seen as a success. Even if it reaches everyone, it will fail if people do not see it as relevant to them or do not know what to do.

This highlights that the real purpose of public warnings is to empower people to make decisions to improve their safety and reduce losses. Warning system designers often ignore this crucial step, and are satisfied when their systems deliver timely alerts, even if these do not result in improved safety. To counter this, we should ask why agencies should be held responsible for people's behaviour when the agency has delivered sound advice? In some 
cases warnings appear to encourage people to take high risk action: a tsunami warning in Queensland prompted many to travel to the coast to witness the arrival of the wave; and flood warnings for the NSW town of Grafton saw many having picnics on the town's levee, which was predicted to overtop (Pfister 2002).

Warnings need to satisfy a range of technical and relatively objective criteria such as accuracy, relevance and timeliness - there is little point receiving warnings after the event. Assuming these conditions are satisfied, the source needs to be seen as credible, and usually official sources in Australia are viewed as credible. Also, the medium and message need to be seen as personally relevant by those at risk. It is important to appreciate that what constitutes a personally relevant message is changing as people's expectations of more specific personalised warning messages are probably increasing. The traditional approach has on occasion managed to do this when the number at risk was small enough to allow each household to be telephoned or doorknocked, but even this level of service has depended on people being at home or a fixed place of work. The UN's Platform for Early Warning (UNISDR 2006) uses the term "people centred warnings" to emphasise that effective warnings need to keep their ultimate purpose in mind and be focused on the needs and expectations of those at risk.

Typically enormous effort has been put into environmental monitoring and detection, with limited effort on achieving shared meaning and sound decision-making with those at risk.

\section{New communication technologies}

New media and mobile technology could bring individual warnings to everyone, anywhere, anytime, but this has yet to occur. New media's attention to peer to peer communication flows and its capacity, through for example crowdsourcing, to provide real time information on unfolding emergencies, does not fit well with the traditional monopolistic supplier model However, it does fit with, and potentially greatly enhances, informal warning networks and systems at every stage of the warning chain.

The near universality of new media and mobile phones, may also be driving expectations among those at risk that they are entitled to expect a personalised warning delivered to their personal mobile device. This would have seemed inconceivable a few years ago, but is starting to become a reality through the Australian Emergency Alert system, and to some extent through a range of twitter and Internet feeds that people can elect to receive on their personal devices.

The Emergency Alert (EA) system is the only official approach currently in use that offers an intrusive warning message to personal devices - whether people have elected to receive it or not. In serious emergencies, warnings are issued via Short Message Service (SMS) text 
messages to mobile phones and voice messages to landlines within a threatened area, however delivery cannot be guaranteed if telecommunications networks are compromised during an event (Australian Government 2009). An informal review of EA found the system was regarded as a convenient, trusted and compelling trigger for action, though possible improvements were identified in relation to the timing, content, accuracy and applicability of messages. While EA has been relatively successful since its nation-wide operational implementation in 2009 (Handmer \& Ratajczak-Juszko 2011), drawbacks within the system have been identified in addition to its reliance on the normal phone system. In some cases, messages are delayed and the information conveyed may be inaccurate.

All web based and phone systems are subject to failure through overloading or power failures, or, and importantly during an emergency, as a result of damage to key facilities. Phone systems have very little if any extra capacity in the name of commercial efficiency. This may make sense for business when blame for failures in such systems can be shifted to governments, but undermines the capacity and reliability of these systems in an emergency. There are also privacy issues with the use of mobile phones for warnings. The launch of the Emergency Alert system in 2009 required a legislative amendment to override privacy provisions governing the use of the national telephone number database (see the Emergency Alert webpage). However, this seems overplayed given that in Australia commercial establishments have access to listed numbers, and charities have access to all numbers including those that are unlisted.

Advantages include the ability of mobiles and the phone network to function during power failures albeit for a limited time. If using the mobile network, warnings can reach people where ever there is phone coverage as most people keep their phones with them. Messages can be closely targeted, for example they can be pre-recorded in different languages and be location based. Text messages do not require people to answer the phone.

New media and mobile technology offers solutions to some of the long standing limitations with warning systems, in particular with personal messages delivered to individuals, and the ability to share information from those at risk using it to improve warnings in real time (for example see Chatfield \& Brajawidagda 2013). Crowdsourced information from twitter is being increasingly drawn on to help provide early warnings in a variety of fields including earthquakes by the United States Geological Survey (Koebler 2013), and by agencies monitoring emerging epidemics.

\section{The potential of satellite positioning systems for warnings}

Global Satellite Navigation Systems (GNSS) have long been recognised as an effective and invaluable technology for providing accurate position information anywhere, anytime on a global scale. These systems include the GPS system of the USA, Russia's GLONASS and 
several other new and emerging constellations such as Europe's Galileo and China's BeiDou systems. There are also regional satellite navigation systems that will become operational in the next few years, particularly from Japan and India.

The new Japanese satellite-based navigation system (Quasi-Zenith Satellite System or QZSS), may play a role in addressing some of the issues raised above with conventional warning systems, as well as providing one approach to meeting contemporary expectations of personal warnings. The uniqueness of this system is that it serves not only as a backup providing redundancy to ground-based telecommunications but also as an extension of an effective emergency response solution. That is, the satellite system has the capacity to deliver alert messages as well as evacuation direction (location-based information) to specific groups and areas, unconstrained by the present limitation of ground-based telecommunications. The QZSS alert message system has been developed and successfully tested in Japan through the Red Rescue Project (see below). In mid 2014, the Japanese and Australian leadership formally agreed to cooperate to promote utilisation of QZSS for emergency management, among other uses. The Japanese satellite consortium has also begun discussion with the European Union, in particular the European Space Agency, to identify needs within the Asian and European countries so that satellite based emergency warning services, standardised across different satellite navigation systems, can be developed to serve Europe and Asia, including Australia.

Europe has been working on emergency message services since 2005 using the European Geostationary Navigation Overlay Service (EGNOS) and European Union's Galileo satellite navigation system with the introduction of the ALIVE (Alert interface via EGNOS) Concept (Mathur et al. 2005). Since then there were follow on projects investigating technical and non-technical benefits as well as advantages of utilising GNSS satellites for disaster alerting (Dixon \& Haas 2008; Wallner 2011; Domínguez et al. 2013). In Japan, investigation to transmit information using the QZSS L1-SAIF signal is currently underway (Iwaizumi \& Kohtake 2013; Sakai \& Hiroe 2012). All these systems include information on the location (i.e., latitude and longitude) of the emergency area and a predefined identifier describes the disaster type.

\section{The Japanese Regional Navigation Satellite Systems}

QZSS is a Japanese regional satellite based augmentation system aimed at enhancing the capabilities of current GNSS systems. When fully deployed in 2018, it will consist of three QZSS satellites placed in Highly Inclined Elliptical Orbits (HEO) and one geostationary satellite. The orbit configuration of these QZSS satellites provides continuous coverage at a high elevation angle, providing improved satellite navigation in areas of Japan that challenge 
traditional GNSS satellite positioning capabilities, such as central city areas. While intended primarily for users in Japan, the orbit design offers significant advantages to neighbouring East Asia countries and Australia. Figure 1 shows the footprint of QZSS satellite. The first QZSS satellite was launched on 11 September 2010.

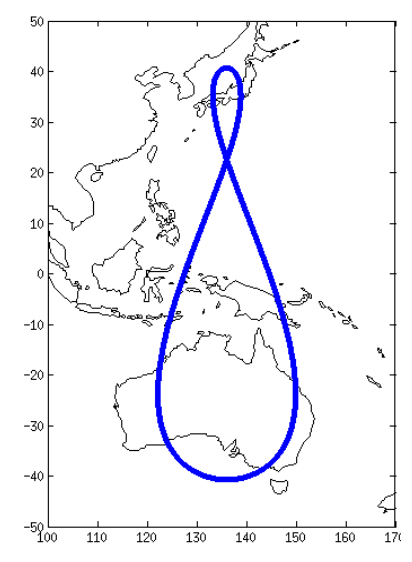

Figure 1: Ground track of QZS-1 orbit.

\section{A Unique Signal}

One unique feature of QZSS is that in addition to the standard GNSS navigation signals, QZSS also has the capability of sending short emergency messages, which none of the current GNSS satellite systems are able to transmit. The messages can be received directly from the satellite by a GPS/GNSS receiver terminal such as in a mobile phone or in-car navigation system. An app would interpret and display the information. Given that mobile phone use and in-car navigation systems are becoming universal with almost everyone involved, the potential coverage and reach of warnings sent to these personal devices is likely to be much greater than the current approaches could achieve.

Another feature of the QZSS provision for alert messaging is that in addition to the wide area coverage provided by the satellite system, the receiver also provides, through their embedded GNSS/GPS capabilities, precise position information. In this way, alert messages can be sent to a specific area depending on the type and content of the disaster information, and only those receivers within the specific area will be activated. Knowing the area of the possible disaster location, the intended users could then be warned, while those outside the disaster area would not be alerted. 
The satellite based system offers a number of advantages for real-time disaster alerts over current approaches to sending warnings via personal devices. A disadvantage is that at present the signal is not generally received indoors. Advantages include:

1) GPS/GNSS with location information can be used during an emergency. This provides the ability to indicate high priority messages for specific areas and groups;

2) The service can cover a wide area simultaneously - e.g. the whole of Australia because of its wide area broadcast footprint, and within the broadcast area, there is no limit to the number of people who can be warned simultaneously;

3) The messages can still be received even when terrestrial communications infrastructure is damaged or not available. This allows for redundancy;

4) As the system is independent of mobile phone coverage it would reach people wherever they are, regardless of the existence of mobile phone coverage.

\section{Red Rescue test project}

The Red Rescue Project (for real-time disaster response using small-capacity data packets from the ubiquitous environment) is supported by the Japanese Government. The project commenced in 2009 as a three-year project and has run trials in Japan and Thailand for tsunami warnings. The project leader is NTT DATA Corporation (a Japanese system integration and data company) and the other project members are Keio University, Asia Air Survey, and Pasco. The authors are collaborating with the Japanese consortium to run a trial in Australia.

The message system: The emergency message is sent to the user from the QZSS satellite using the L1-SAIF (Submetre-class Augmentation with Integrity Function) signal. This signal is broadcasted on the L1 frequency band (1575.42 MHz). The advantage of the L1 signal is that it is the most widely used signal by the mass-market GNSS/GPS receivers. All, if not most, GNSS/GPS receivers are able to track and acquire this signal. At 212 bits, each emergency message is very short, but a number of messages can be combined to produce a longer message.

Fig. 2 shows a schematic diagram of the QZSS alert messaging transmission system. The system consists of three parts: the transmission, satellite and user segments. 


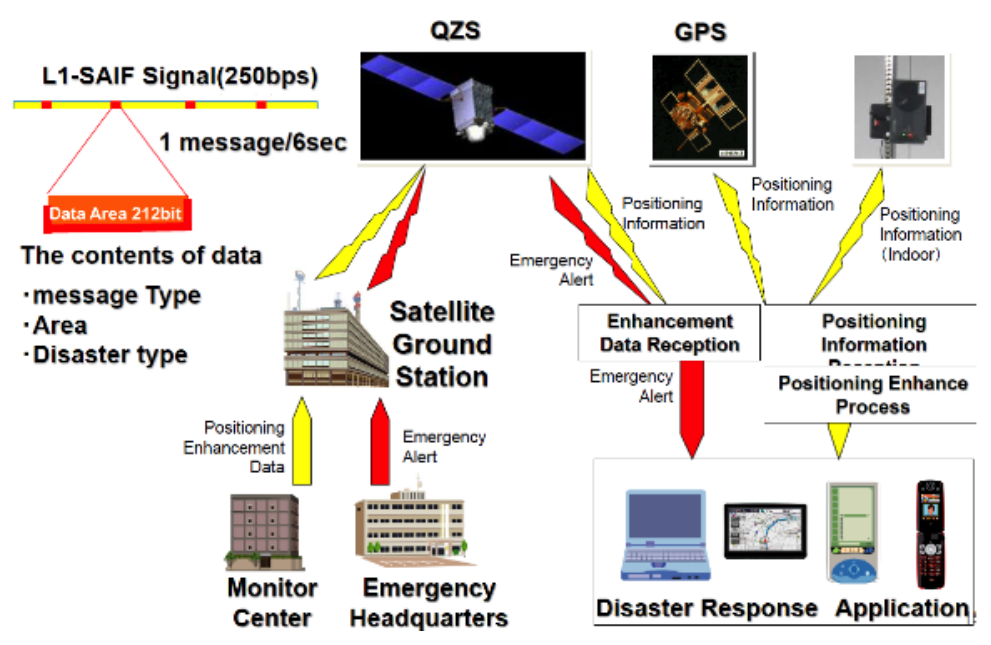

Figure 2. QZSS alert messaging transmission system.

The Transmission Segment. This segment consists of the Disaster Management Centre, the Monitor Centre, and the Satellite Ground Control Station.

The transmission segment transmits disaster messages to the satellite segment in the following order: First, the Disaster Management Centre gathers the relevant information. Second, the Disaster Management Centre converts the information into an emergency message for transmission by QZSS. The Disaster Management Centre decides the distribution schedule for providing the information and transmits the emergency message to the Satellite Ground Control Station. Third, the Ground Control Station collects the Monitor Centre's results and generates (enhanced) navigation messages for broadcast on the L1-SAIF signal, which will be used by the user to derive precise position information The Ground Control Station uplinks both the navigation message and the emergency message to the QZSS satellites.

The Satellite Segment. The satellite segment consists of both the QZSS and other GNSS satellites like GPS. The L1-SAIF signal with the enhanced navigation message and the superimposed emergency message are transmitted to the users.

The User Segment. The users receives the L1-SAIF signal and position information from QZSS as well as position information from other GNSS satellites on their GNSS receivers. The enhanced navigation message is used to provide accurate position of the users. The L1SAIF signal contains the emergency message that is decoded by the users' device by an app in order to acquire the disaster information.

For the QZSS alert messaging system, two receiving modes are being developed: One is the wide-area broadcast mode, which can send emergency message simultaneously over a large area; the other is the area-selected broadcast mode, which can send messages to a specified 
area (Iwaizumi et al 2014). The area-selected mode delivers several emergency messages to provide disaster information for all areas depending on the type and content of the disaster information. Therefore, the user segment of this system provides the disaster information to the users by selecting the information of the area corresponding to the location of the user from the received emergency messages (Iwaizumi et al. 2014).

\section{Conclusions}

We identified a disjunction between the way warning systems are conventionally conceptualised, and the expectations of the public for personal warnings and the realities of contemporary information flows through social media and mobile technologies. To meet this need aspects of mobile technology are now being employed by Australian emergency services through the Emergency Alert system, which delivers a standard text message warning or alert to mobile phones. However, the monopolistic supplier model is not intended to absorb the real time information available via crowd sourcing. In addition, mobile phones and the mobile phone network have many limitations. Nevertheless, some agencies in Australia and elsewhere are starting to incorporate crowd sourced information, in particular from twitter, into their monitoring and warning systems.

The Japanese satellite system is also a supply driven approach, although it would deliver messages to people's personal devices which could be tailored to their circumstances via apps. It has the potential therefore to address one of the shortcomings of the traditional model. It is not likely to become a replacement for existing systems, but it can augment and strengthen them by providing an independent way of sending warnings. This developing system has the capacity to transmit messages to mobiles phones and in-car navigation units for disaster warning and response via the GNSS location capacity now part of all smart phones, rather than through the phone networks. This approach appears to offer significant advantages over current systems: it is not reliant on ground based telecommunications infrastructure and can provide warnings anywhere to anyone in a defined location. It could also provide a backup system when local communications infrastructure fails. It is not affected by telecommunication traffic congestion and can warn millions of people simultaneously, providing both a way to distribute urgent messages as well as surge capacity for wide-area warnings.

An Australian trial of the QZSS satellite warning system is planned for 2015. A major challenge is how this system and other existing systems can take advantage of crowd sourced information, and the informal networks facilitated by social media. 


\section{Acknowledgements}

We thank the RMIT University Science, Engineering and Health College Research \& Innovation Office, the Bushfire and Natural Hazards Cooperative Research Centre (BNHCRC) and the RMIT School of Mathematical and Geospatial Sciences for providing funding for the project, "Next Generation Warning Systems", which this paper draws from. We also acknowledge our collaborators on the project: Dr Joshua Whittaker and Dr Marc Demange of RMIT and Dr Michael Rumzewicz of the BNHCRC.

\section{References}

Australian Government. 2009. News Release. 'Rudd Government Implements COAG Agreement on Telephone-Based Emergency Warning Systems,' 23 February 2009, Canberra. Available at: http://www.royalcommission.vic.gov.au/Documents/Documentfiles/Exhibits/WIT-032-001-0261.pdf

BTE. 2001. Bureau of Transport Economics, The Economic Costs of Natural Disasters in Australia. Canberra.

Chatfield, AT; Brajawidagda, U. 2013. Twitter Early Tsunami Warning System: A Case Study in Indonesia's Natural Disaster Management, System Sciences (HICSS), 201346 Hawaii International Conference, DOI: 10.1109/HICSS.2013.579.

Dixon, CS; Haas, R. 2008. GNSS User Requirements in Emergency Management, RIV NAV'o8 Conference, London, UK.

Domínguez, E; Simón, FJ; Thomas, P; Zheng, Y; Wittmann, E; Lekaim, D; Tossaint, M; Jeannot, M. 2013. ESA's Multi-Constellation Regional System Land Users Test-Bed Integrity Algorithms Experimentation Results, to be presented at the 26th International Technical Meeting of The Satellite Division of the Institute of Navigation (ION GNSS 2013), Nashville, TN, September 2013

EMA. 2009. Emergency Management Australia. Flood warning: an Australian guide ( $3^{\text {rd }}$ Edition), Emergency Management Australia, Canberra. Emergency Alert. Available at: http://www.emergencyalert.gov.au/frequently-asked-questions/who-can-use-it.html. For the actual amendment see: http://www.austlii.edu.au/au/legis/cth/num act/tapnda2009556/sch1.html. Page accessed 12 November 2014.

Handmer, J. 2000. Are flood warnings futile? The Australasian Journal of Disaster and Trauma Studies. Available at: http://www.massey.ac.nz/ trauma/issues/2000-2/ (2000-2) ISSN: 1174-4707. 
Handmer, J. 2006. American exceptionalism or universal lesson: the implications of Hurricane Katrina for Australia, Australian Journal of Emergency Management. 21(1) Feb 2006, 29-42.

Handmer, J. 2009. Warnings and information, Prepared for the 2009 Victorian Bushfires

Royal Commission, Centre for Risk and Community Safety, RMIT University. May 2009.

Witness Statement - 044-001-0002-R.

Handmer, J; Ratajczak-Juszko, I. 2011, Systematic Review of Reports on Emergency Alert,

Report prepared for the Office of the Emergency Services Commissioner by the Centre for Risk and Community Safety, RMIT University, Melbourne

Iwaizumi, D; Ishida, T; Iino, S; Kohtake, N; Buist, P. 2014 GNSS-based Emergency Message

Service: Lesson Learned and Future Prospects, $7^{\text {th }}$ Advanced Satellite Multimedia Systems

Conference, $13^{\text {th }}$ Signal Processing for Space Communications Workshop, 8 - 10

September 2014 .

Iwaizumi, D; Kohtake, N. 2013. Evaluation of reachability and promptness in delivering disaster and evacuation information using an augmentation signal of the QZSS system, $64^{\text {th }}$ IAC, Beijing, China, 2013.

Koebler, J. 2013. The USGS is tracking earthquakes with Twitter, Motherboard. Available at: http://motherboard.vice.com/blog/the-usgs-is-tracking-earthquakes-with-twitter. Accessed 20 November 2014.

Mathur, AR; Ventura Traveset, J; Montefusco, C; Toran, F; Plag, HP; Ruiz, L; Levy, J. 2005. Provision of emergency communication messages through SBAS: The ESA ALIVE concept, ION GNSS 2005, Long Beach, US.

Parker, DJ; Handmer, J. 1998. The role of unofficial flood warning systems, Journal of Contingencies and Crisis Management, 6(1), 45-6o.

Pfister, N. 2002. Community response to flood warnings: the case of an evacuation from Grafton, Australian Journal of Emergency Management, Vol 17, No 2. Available at: https://ajem.infoservices.com.au/items/AJEM-25-02-09\#sthash.mNiBnC1c.dpuf

Sakai, T; Hiroe, N. 2012. Broadcasting Nationwide Emergency Message by QZSS L1-SAIF Signal, presented at the Proceedings of the 2012 IEICE General Conference, 2012.

UN-ISDR. 2006. Developing Early warning Systems: a checklist. Available at: http://www.unisdr.org/2006/ppew/info-resources/ewc3/checklist/English.pdf 
Wallner, S. 2011. Status of Definition of Dissemination of Emergency Alerts through GNSS, presented at the Sixth Meeting of the International Committee on Global Navigation Satellite Systems (ICG), Working Group B: Enhancement of performance of GNSS services, organized by the Government of Japan, Tokyo, Japan, 5 - 9 September 2011 